\title{
An overview on congenital dental anomalies
}

\author{
Ameera Ibrahim Amer ${ }^{1}$, Sultan Hasan Al Harbi², Sarah Salem Alshudukhi ${ }^{3}$, \\ Ashwaq Ibrahim Alanazi ${ }^{4}$, Abdullah Salem Bakhuraybah ${ }^{5}$, Samirah Hashim Jabir ${ }^{6}$, \\ Waleed Shabeeb Alrasheedi ${ }^{6}$, Renad Waheeb Attar ${ }^{5}$, Basel Khalid Alsadoon ${ }^{7}$, \\ Anwar Hassan Hakami ${ }^{8}$, Majed Abdullah Almalki ${ }^{9}$
}

\author{
${ }^{1}$ Department of Pediatric Dentistry, East Jeddah Hospital, Jeddah, Saudi Arabia \\ ${ }^{2}$ Dental Department, Buraidah Central Hospital, Buraidah, Saudi Arabia \\ ${ }^{3}$ Hail Dental Center, Ministry of Health, Hail, Saudi Arabia \\ ${ }^{4}$ Qurayat General Hospital, Ministry of Health, Qurayat, Saudi Arabia \\ ${ }^{5}$ College of Dentistry, King Abdulaziz University, Jeddah, Saudi Arabia \\ ${ }^{6}$ Ministry of Health, Hail, Saudi Arabia \\ ${ }^{7}$ College of Dentistry, University of Hail, Hail, Saudi Arabia \\ ${ }^{8} \mathrm{Al}$ Sundos Dental Clinics, Jeddah, Saudi Arabia \\ ${ }^{9}$ College of Dentistry, King Abdulaziz University Hospital, Jeddah, Saudi Arabia
}

Received: 25 December 2021

Revised: 11 January 2022

Accepted: 12 January 2022

\section{*Correspondence:}

Dr. Ameera Ibrahim Amer,

E-mail: ameera-dent@hotmail.com

Copyright: (C) the author(s), publisher and licensee Medip Academy. This is an open-access article distributed under the terms of the Creative Commons Attribution Non-Commercial License, which permits unrestricted non-commercial use, distribution, and reproduction in any medium, provided the original work is properly cited.

\begin{abstract}
Congenital anomalies pose a huge threat to the affected and susceptible individuals and significantly impair their lives. In addition, congenital dental anomalies are also a serious issue and can be associated with certain complications. It has been shown the development of these disorders might be found as a single disorder or part of another systemic syndrome. The present literature review provides an overview of congenital dental anomalies. Different congenital anomalies can be detected, including tooth rotation, taurodontism, hypodentition, hyperventilation, Dens evaginatus, Dens invaginatus, Talson cusps, supernumerary roots, dilaceration, concrescence, fusion, and gemination. These conditions might complicate underlying dental physiology and make it difficult to conduct various treatment modalities. Furthermore, the epidemiology of these disorders is inconsistent among the different worldwide investigations. For instance, some studies reported that hypo-and hyperdentition are the most commonly reported anomalies, while others showed that tooth rotation might be the most common anomaly. Further evidence is still needed before making solid conclusions regarding the epidemiology of these disorders.
\end{abstract}

Keywords: Congenital anomalies, Dentition, Dentistry, Genetics tooth rotation, Hypodentition, Hyperdentition, Gemination, Fusion

\section{INTRODUCTION}

Disturbances during tooth development can define dental anomalies. Dental anomalies represent a vital set of conditions that can significantly impair the dental pathology for both deciduous and permanent teeth. Dental anomalies are relatively common among different populations, and estimates show that $36.7 \%-40.3 \%$ of individuals usually suffer from $\geq 1$ dental anomaly., These disorders also have different forms of presentation, including degree, number, size, shape, and color of teeth. ${ }^{3}$ Evidence shows that the etiology of these conditions is not generally comprehended. However, some studies 
indicate that genetic and environmental causes might predispose to the pathology of these disorders. ${ }^{2}$

Congenital anomalies pose a huge threat to the affected and susceptible individuals and significantly impair their lives. In addition, congenital dental anomalies are also a serious issue and can be associated with certain complications. It has been shown the development of these disorders might be found as a single disorder or part of another systemic syndrome. Evidence shows that the prevalence of orofacial disturbances among children is $7 \% .^{4,5}$ There are different dental congenital anomalies in the literature with huge variations regarding epidemiological data. We are conducting the current literature review to provide an overview of congenital dental anomalies based on evidence from studies in the literature.

\section{LITERATURE REVIEW}

This literature review is based on an extensive literature search in Medline, Cochrane, and EMBASE databases on which was performed $3^{\text {rd }}$ December 2021 using the medical subject headings (MeSH) or a combination of all possible related terms, according to the database. To avoid missing poetential studies, a further manual search for papers was done through Google Scholar, while the reference lists of the initially included papers. Studies discussing congenital dental anomalies were screened for useful information, with no limitations posed on date, language, age of participants, or publication type.

\section{DISCUSSION}

Among the relevant studies in the literature, it has been demonstrated that various congenital dental anomalies can be found in children. These include taurodontism, dens evaginatus, dens invaginatus, talson cusps, supernumerary roots, dilaceration, concrescence, fusion, and gemination. Evidence shows that the definition of germination and fusion is the presence of double teeth that are usually observed to have a greater size than the standard tooth. Furthermore, it has been reported that fusion can be referred to as counting the anomalous tooth as one while the augmented teeth with teeth count less than normal. ${ }^{6,7}$ On the other hand, germination is usually observed when there are united teeth or abnormally enlarged teeth, which count more than normal when the abnormal tooth has been counted as one tooth. ${ }^{8}$ Many complications and adverse events can develop secondary to the presence of these anomalies. These include reduced space for the eruption of adjacent teeth, crowding of teeth, and compromised esthetics. ${ }^{9,10}$ The prevalence of these disorders will be discussed later in this discussion based on information from various relevant investigations. In another context, authors usually define concrescence as the fusion of two adjacent teeth through their cementum. Such complication is usually associated with serious difficulties regarding teeth endodontic and surgical treatment. Moreover, it has been demonstrated that it is usually difficult to perform proper periodontal and orthodontic approaches when these anomalies are reported. ${ }^{11}$ The prevalence of this condition is not high compared with other anomalies. For instance, a previous study in France estimated that the prevalence of concrescence was $0.36 \%$ in their population. ${ }^{12}$ On the other hand, other studies were also reported in India. These studies reported that the prevalence of the condition is variable, ranging between $0.019 \%$ and $0.09 \%$. Moreover, there were inconsistencies among these studies regarding the effect of gender on prevalence rates, as some studies showed that the prevalence was higher among males. In contrast, others reported that it was higher among females. This might be justified by the different recruitment procedures, demographics, general epidemiology of congenital dental anomalies per country, and different diagnostic criteria. ${ }^{11}$

Dilaceration is usually defined as the presence of an atypical bend in the crown or root of teeth. Evidence shows that this anomaly is usually observed in the root of the tooth. However, it has been reported that it can affect any part of the tooth. In addition, it has been furtherly reported that different complications might occur with this anomaly. Accordingly, clinicians might find it difficult to conduct endodontic and surgical treatment approaches. The prevalence of the condition is also inconsistent among the various worldwide investigations. Among them, the prevalence seems to range between $0.18 \%$ and $16.48 \% .^{9,12-16}$ Moreover, a previous study in India reported that the prevalence is usually more common among females. ${ }^{13}$ Supernumerary roots can be identified as the development of extra roots to one tooth more than normally observed. Different areas and teeth can be affected, including molars, premolars, and canines. Evidence indicates that third molars are the most commonly affected, and these anomalies usually occur in the mandibular region. The prevalence of the condition among children is also variable among the different studies and ranges between $0.034 \%$ and $5.9 \%$. The significant differences in prevalence rates might be attributed to gender, geographical distribution and demographics of populations, and ethnicity. ${ }^{9,17-19}$

Various studies in the literature have reported various types and frequencies of dental anomalies in children. These anomalies might be attributed to many causes, including genetic mutation, being part of another congenital systemic syndrome, and following cancer treatment. In the present section, we will provide an overview of these congenital anomalies based on evidence from current studies in the literature. For example, a previous study in Taiwan by Chen et al reported that the prevalence of hyper-and hypodontia in their cohort was $<1 \%$ and $2 \%$, respectively. ${ }^{20}$ Moreover, the prevalence of double teeth was estimated to be $3 \%$. It should be noted that no significant differences were noticed in terms of the prevalence rates of dental anomalies between both sexes. Another investigation in India also examined school children for detecting dental 
anomalies. The authors demonstrated that hypodentition and double bite were the most commonly reported dental anomalies in their cohort. In addition, it has been estimated that the prevalence of fusion and gemination, hypodontia, and unilateral anterior and posterior bites were $0.5 \%, 0.4 \%, 0.1 \%$, and $0.8 \%$, respectively. ${ }^{21}$ Another Taiwanese national survey demonstrated that the prevalence of dental anomalies among children $(<6$ years old), including double teeth in primary dentition, hypodontia, and talon cusp, were $2.14 \%, 1.33 \%$, and $0.61 \%$, respectively. ${ }^{22}$ The significant differences among these worldwide investigations indicate the impact of ethnic and geographical distribution on children's development of dental anomalies..$^{23,24}$

Studies in Saudi Arabia were also conducted and reported the epidemiology and patterns of dental anomalies in the kingdom. For instance, a previous investigation in the Abha region by Yassin reported that hypo-and hyperdontia were the most common dental anomalies in their children, prevalent in $9.7 \%$ and $3.5 \%$, respectively. Other dental anomalies were also reported, including micro-and macrodontia, talon cusp, taurodontism, fusion, ectopic eruption, rotation, amelogenesis imperfecta, and dentinogenesis imperfecta $(2.6 \%, 1.8 \%, 1.4 \%, 0.8 \%$, $2.3 \%, 0.4 \%, 0.3 \%$, and 0.1 , respectively). It has been furtherly reported that the prevalence of dental anomalies was significantly different between male and female children. ${ }^{14}$ This was also previously reported in another similar Turkish investigation. ${ }^{25}$ Another investigation in Eastern Saudi Arabia was also conducted to evaluate the epidemiology of non-syndromic dental anomalies among children. It has been reported that teeth rotations were the most commonly reported tooth anomaly in their population $(24.5 \%)$. Many other congenital anomalies were reported in this study, including ectopic teeth eruption, the congenital missing of permanent teeth, peg lateral, supernumerary, gemination, and fusion (6\%, $5.4 \%, 1.1 \%, 0.5 \%, 0.3 \%$, and $0.1 \%$, respectively). Moreover, it has been reported that the prevalence of dental anomalies in this population was not significantly impacted by nationality, medical history, or gender. ${ }^{26}$ In this context, Afify and Zawai conducted a previous study in the Western region. The authors reported that congenital teeth missing and impacted teeth were the most common congenital anomalies in their population, with estimated rates of $25.7 \%$, and $21.1 \%$, respectively. Moreover, the authors estimated that other dental anomalies were also reported in their population, including taurodontisim $(0.1 \%)$, supernumerary teeth $(0.3 \%)$, and root dilacerations $(1.1 \%)$. However, it should be noted that the study did not consist of children only and included patients with an age range of 2-30 years old. ${ }^{27}$ Another investigation was also conducted in the Eastern region by $\mathrm{AL}$ Humaid et al and included participants aged 7-65 years old. Again, the authors estimated that the most common dental anomalies in their population were teeth dilaceration, congenitally missing teeth, supernumerary teeth, taurodontism, and talon cusp $(30.2 \%, 24.7 \%, 1.8 \%, 0.1 \%$, and $0.1 \%$, respectively). It should be noted that there was a significant difference between males and females regarding the prevalence of dental anomalies. Moreover, the prevalence of anomalies in the pediatric population was found to be $1.5 \%$ only. ${ }^{28}$ Another investigation in Saudi Arabia also demonstrated that the prevalence of dental anomalies was remarkably higher among orthodontically treated children than within the general population. ${ }^{29}$

The prevalence of tooth rotation is hugely variable across the different investigations worldwide. For instance, a previous study in India reported that tooth rotation was the most common dental anomaly in their population, prevalent in $10.24 \%$ of them. ${ }^{30}$ However, another study from India also reported a similar rate of teeth rotation in their population $(13.17 \%){ }^{31}$ Evidence shows that many etiologies can attribute to the development of teeth rotation anomalies in children. These include disturbances within the post-and pre-eruptive phases, owing to many causes that include supernumerary teeth, hypodontia, ectopically erupted teeth, teeth extractions, tumors, cysts, and traumas. ${ }^{14,32,33}$ Evidence also indicates no apparent etiology for the development of ectopic eruption. However, it has been suggested that both local and genetic factors might be involved in the etiology of this condition. Many local factors were reported in this context. These include abnormal crown morphology of primary second molar, deviations in the eruption path, bone growth at tuberosity area, inadequate anteroposterior growth of the jaws, early eruption of the maxillary first permanent molar, and small arches. ${ }^{34,35}$ Many relevant studies reported that ectopic eruption was among children's most common congenital dental anomalies. $^{30,33,36}$

Among the most common dental anomalies, evidence shows that congenitally missing teeth might be a significant issue for the affected children. This might be due to relevant aesthetic, functional, nutritional, and linguistic errors that might develop secondary to tooth loss. Accordingly, it has been demonstrated that these events usually require a comprehensive multidisciplinary management approach. ${ }^{17}$ Previous studies also reported that the epidemiology of congenital teeth loss might be significantly different among different ethnic groups. ${ }^{14,36}$ For example, in Saudi Arabia, estimates show that the prevalence of congenital teeth loss ranges between $2.2 \%$ and $9.7 \% .^{14,37,38}$ However, other worldwide investigations show that the condition's prevalence might be up to $7.1 \% \cdot{ }^{17,25,39}$ It has been furtherly demonstrated that the prevalence of fusion anomalies is inconsistent among different studies and populations. This has been attributed to the impact of genetic, racial, and geographic factors on the prevalence of these anomalies. Finally, it should be noted that the prevalence of this condition is not very high among other various congenital anomalies in children, which is usually $\leq 0.5 \% .^{21,38,40}$ The definition of supernumerary teeth includes teeth that develop adjacent to the normal dentition. It has been demonstrated that these anomalies usually predispose to crowding, delayed 
eruption, dental impaction, a diastema, and cystic lesions. ${ }^{39,41}$ It should be noted that the prevalence of this condition is not also common among the different relevant studies in the literature. However, variations are still present, usually attributed to the different diagnostic criteria, demographics, and sample size.

\section{CONCLUSION}

Different congenital anomalies including tooth rotation, taurodontism, hypodentition, hyperventilation, dens evaginatus, dens invaginatus, Talson cusps, supernumerary roots, dilaceration, concrescence, fusion, and gemination are found in the pediatrics. These conditions might complicate underlying dental physiology and make it difficult to conduct various treatment modalities. Furthermore, the epidemiology of these disorders is inconsistent among the different worldwide investigations. For instance, some studies reported that hypo-and hyperdentition are the most commonly reported anomalies, while others showed that tooth rotation might be the most common anomaly. Further evidence is still needed before making solid conclusions regarding the epidemiology of these disorders.

\section{Funding: No funding sources Conflict of interest: None declared \\ Ethical approval: Not required}

\section{REFERENCES}

1. Patil S, Doni B, Kaswan S, Rahman F. Prevalence of dental anomalies in Indian population. J Clin Exp Dentistry. 2013;5(4):e183.

2. Uslu O, Akcam MO, Evirgen S, Cebeci I. Prevalence of dental anomalies in various malocclusions. Am J Orthodontics Dentofacial Orthop. 2009;135(3):32835 .

3. Årtun J, Van't Hullenaar R, Doppel D, KuijpersJagtman AM. Identification of orthodontic patients at risk of severe apical root resorption. Am J Orthodont Dentofacial Orthop. 2009;135(4):448-55.

4. Maas R, Bei M. The genetic control of early tooth development. Crit Rev Oral Biol Med. 1997;8(1):439.

5. Berkovitz BK, Holland G, Moxham BJ. Oral Anatomy, Histology and Embryology E-Book. Elsevier Health Sci. 2017.

6. Son PT, Reda A, Viet DC. Exchange transfusion in the management of critical pertussis in young infants: a case series. Vox Sang. 2021;116(9):976-82.

7. El-Qushayri AE, Ghozy S, Reda A, Kamel AMA, Abbas AS, Dmytriw AA. The impact of Parkinson's disease on manifestations and outcomes of COVID19 patients: A systematic review and meta-analysis. Rev Med Virol. 2021:e2278.

8. Vasudev SK, Goel BR. Endodontic management of dens evaginatus of maxillary central incisors: a rare case report. J Endodontics. 2005;31(1):67-70.
9. Guttal KS, Naikmasur VG, Bhargava P, Bathi RJ. Frequency of developmental dental anomalies in the Indian population. Eur J Dentistry. 2010;4(3):263-9.

10. Olivan-Rosas G, López-Jiménez J, Giménez-Prats MJ, Piqueras-Hernández M. Considerations and differences in the treatment of a fused tooth. Medicina Oral. 2004;9(3):224-8.

11. Goswami M, Bhardwaj S, Grewal N. Prevalence of Shape-related Developmental Dental Anomalies in India: A Retrospective Study. Int J Clin Pediatr Dentistry. 2020;13(4):407-11.

12. Baron C, Houchmand-Cuny M, Enkel B, LopezCazaux S. Prevalence of dental anomalies in French orthodontic patients: A retrospective study. Arch De Pediatr. 2018;25(7):426-30.

13. Goutham B, Bhuyan L, Chinnannavar SN, Kundu M, Jha K, Behura SS. Prevalence of Dental Anomalies in Odisha Population: A Panoramic Radiographic Study. J Contemp Dent Pract. 2017;18(7):549-53.

14. Yassin SM. Prevalence and distribution of selected dental anomalies among saudi children in Abha, Saudi Arabia. J Clin Exp Dentistry. 2016;8(5):e48590.

15. Nguyen TM, Huan VT, Reda A. Clinical features and outcomes of neonatal dengue at the Children's Hospital 1, Ho Chi Minh, Vietnam. J Clin Virol. 2021;138:104758.

16. Thieu H, Bach Dat B, Nam NH. Antibiotic resistance of Helicobacter pylori infection in a children's hospital in Vietnam: prevalence and associated factors. Minerva Medica. 2020;111(5):498-501.

17. Fekonja A. Prevalence of dental developmental anomalies of permanent teeth in children and their influence on esthetics. J Esthetic Restorative Dentistry. 2017;29(4):276-83.

18. Saberi EA, Ebrahimipour S. Evaluation of developmental dental anomalies in digital panoramic radiographs in Southeast Iranian Population. J Int Society Preventive Community Dentistry. 2016;6(4):291-5.

19. Schäfer E, Breuer D, Janzen S. The prevalence of three-rooted mandibular permanent first molars in a German population. J Endodontics. 2009;35(2):2025.

20. Chen YH, Cheng NC, Wang YB, Yang CY. Prevalence of congenital dental anomalies in the primary dentition in Taiwan. Pediatr Dentistry. 2010;32(7):525-9.

21. Lochib S, Indushekar KR, Saraf BG, Sheoran N, Sardana D. Occlusal characteristics and prevalence of associated dental anomalies in the primary dentition. J Epidemiol Glob Health. 2015;5(2):151-7.

22. Chang PS, Yen TH, Huang CJ, Yen AM, Chen SL, Tsai AI. Clinical Orodental Anomalies in Taiwanese Children under Age Six: a Study Based on the 19951997 National Dental Survey. BioMed Res Int. 2020;2020:2056340.

23. El-Qushayri AE, Dahy A, Reda A. A closer look at the high burden of psychiatric disorders among 
healthcare workers in Egypt during the COVID-19 pandemic. Epidemiol Health. 2021;43:e2021045.

24. Pham TS, Reda A, Ngan Nguyen TT. Blood exchange transfusion in viral hepatitis in a small infant: a case report. Transfusion Apheresis Sci. 2020;59(6):102907.

25. Karadas M, Celikoglu M, Akdag MS. Evaluation of tooth number anomalies in a subpopulation of the North-East of Turkey. Eur J Dentistry. 2014;8(3):337-41.

26. Bakhurji EA, Aldossary F, Aljarbo J, AlMuhammadi F, Alghamdi M, Nazir MA. Prevalence and Distribution of Nonsyndromic Dental Anomalies in Children in Eastern Saudi Arabia: A Radiographic Study. Scientific World J. 2021;2021:9914670.

27. Afify AR, Zawawi KH. The Prevalence of Dental Anomalies in the Western Region of Saudi Arabia. Dentistry. 2012;2012:837270.

28. Alhumaid J, Buholayka M, Thapasum A, Alhareky M, Abdelsalam M, Bughsan A. Investigating prevalence of dental anomalies in Eastern Province of Saudi Arabia through digital orthopantomogram. Saudi J Bio Sci. 2021;28(5):2900-2906.

29. Al-Jabaa A, Aldrees A. Prevalence of Dental Anomalies in Saudi Orthodontic Patients. J Contemporary Dental Practice. 2013;14:724-30.

30. Gupta P, Gupta N, Gupta R, Arora V, Mehta N. The prevalence of oro-dental anomalies among 14-17 years students in Panchkula District Haryana, India. J Dentistry Oral Hygiene. 2015;7(4):44-7.

31. Kathariya MD, Nikam AP, Chopra K, Patil NN, Raheja H, Kathariya R. Prevalence of Dental Anomalies among School Going Children in India. J Int Oral Health. 2013;5(5):10-4.

32. Jung YH, Kim JY, Cho BH. The effects of impacted premaxillary supernumerary teeth on permanent incisors. Imaging Sci Dentistry. 2016;46(4):251-8.
33. Vani NV, Saleh SM, Tubaigy FM, Idris A. Prevalence of developmental dental anomalies among adult population of Jazan, Saudi Arabia. Saudi J Dental Res. 2016;7(1):29-33.

34. Yaseen SM, Naik S, Uloopi KS. Ectopic eruption-A review and case report. Contemporary Clin Dentistry. 2011;2(1):3-7.

35. Güven Y. Prevalence of ectopic eruption of first permanent molars in a Turkish population. Eur Oral Res. 2018;52(1):1-5.

36. Afify AR, Zawawi KH. The prevalence of dental anomalies in the Western region of saudi arabia. ISRN Dentistry. 2012;2012:837270.

37. Osuji OO, Hardie J. Dental anomalies in a population of Saudi Arabian children in Tabuk. SDJ-Saudi Dental J. 2002:11-4.

38. Salem G. Prevalence of selected dental anomalies in Saudi children from Gizan region. Community Dentistry Oral Epidemiol. 1989;17(3):162-3.

39. Laganà G, Venza N, Borzabadi-Farahani A, Fabi F, Danesi C, Cozza P. Dental anomalies: prevalence and associations between them in a large sample of non-orthodontic subjects, a cross-sectional study. BMC Oral Health. 2017;17(1):62.

40. Bäckman B, Wahlin YB. Variations in number and morphology of permanent teeth in 7-year-old Swedish children. Int J Paediatr Dentistry. 2001;11(1):11-7.

41. Al-Jabaa AH, Aldrees AM. Prevalence of dental anomalies in Saudi orthodontic patients. J Contemp Dent Pract. 2013;14(4):724-30.

Cite this article as: Amer $\mathrm{AI}, \mathrm{Al}$ Harbi SH, Alshudukhi SS, Alanazi AI, Bakhuraybah AS, Jabir $\mathrm{SH}$ et al. An overview on congenital dental anomalies. Int J Community Med Public Health 2022;9:976-80. 